\title{
Vaginal pessary in advanced pelvic organ prolapse: impact on quality of life
}

\author{
Barbara Bevilacqua Zeiger ${ }^{1}$ (D) Silvia da Silva Carramão ${ }^{1} \cdot$ Carlos Antônio Del Roy $^{2} \cdot$ Thais Travassos da Silva $^{1}$. \\ Susane Mei Hwang ${ }^{1}$. Antonio Pedro Flores Auge ${ }^{1}$
}

Received: 24 June 2021 / Accepted: 15 September 2021 / Published online: 6 November 2021

(c) The International Urogynecological Association 2021

\begin{abstract}
Introduction and hypothesis Pelvic organ prolapse (POP) is a highly prevalent dysfunction of the pelvic floor affecting up to $40 \%$ of women. The symptoms of POP have a major impact on quality of life. Pessary treatment is a therapy option associated with high levels of satisfaction and few complications.

Objectives The objective was to assess the impact and efficacy of vaginal pessary use on the quality of life of women with advanced POP stages III and IV.

Materials and methods A multicenter, longitudinal, prospective observational study was conducted at the Urogynecology Sector of the Hospital Ipiranga and the Hospital Central of the Irmandade da Santa Casa de Misericórdia de São Paulo. A sociodemographic questionnaire was employed and two scales validated in Portuguese (ICIQVS and SF 12) were applied before and 6 months after pessary use. Student's $t$ test, Mann-Whitney test and Fisher's exact test were applied, adopting a significance level of 0.05 .

Results The median age of participants was 71.5 (65-76) years and the median number of pregnancies was 4 (3-5). Deliveries were predominantly vaginal (82.5\%). Women sexually active (16.49\%) showed improvement in sexual function $(78.6 \%)$. The participants showed improvement in vaginal symptoms $(91.8 \%)$ and quality of life $(92.8 \%)(p<0.01)$ post-treatment. Of the total 97 women, the sample drop-out rate was $9.3 \%$ and 88 participants completed the two stages of the study.

Conclusions Vaginal pessary use had $90.7 \%$ efficacy, a high level of treatment satisfaction (75.3\%), and a positive impact on the improvement of vaginal and sexual symptoms, quality of life, and mental health.
\end{abstract}

Keywords Pelvic Organ Prolapse · Conservative Treatment · Quality of Life · Mental Health · Questionnaires

\section{Introduction}

Pelvic floor dysfunctions (PFD) include urinary incontinence, pelvic organ prolapse (POP), fecal or anal incontinence, chronic pelvic pain, and sexual or anorectal dysfunction [1]. In the USA, pelvic floor disorders account for roughly 300,000 surgical procedures per year, representing annual costs of 1 billion dollars [2-4]. In Brazil, according to data from DATASUS (2000) [5] POP is responsible

Barbara Bevilacqua Zeiger

drabazeiger@icloud.com

1 Santa Casa de Sao Paulo School of Medical Sciences, Rua Dr. Cesário Motta Jr.,61, São Paulo, SP CEP 01221020, Brazil

2 Federal University of São Paulo - UNIFESP, São Paulo, SP, Brazil for over 160,0000 hospital admissions per year nationwide. (http://datasus.saude.gov.br/informacoes-de-saude/tabnet/ demograficas-e-socioeconomicas).

Pelvic organ prolapse is a highly prevalent dysfunction of the pelvic floor that affects around $40 \%$ of women, particularly females who are older, multiparous, and white [6], and represents a major global public health challenge.

Increased life expectancy is closely associated with risk factors related to the development of POP, and gynecologists, urogynecologists, nurses, and physiotherapists should be increasingly prepared to deal with possible approaches to this condition [7].

The physiopathology of POP is recognized for being multifactorial and develops gradually over a period of years. This POP is the result of an imbalance in the forces responsible for pelvic support, which keep the uterus and other organs within the pelvis [8]. 
A diagnosis of POP ideally demands clear clinical evidence, starting with a woman having symptoms related to the "downward displacement" of a pelvic organ [9].

Uterine prolapse in pregnancy is a rare condition. The form of management reported in the literature is conservative treatment. The use of a vaginal pessary is a good strategy once young women intend to get pregnant and avoid surgical procedures [10].

Vaginal pessaries have been used for millennia, with reports as early as $400 \mathrm{BC}$. Hippocrates described the reduction of vaginal drooping using a pomegranate soaked in wine within the vagina [11]. Pessaries have been in use in the USA and Europe for over 70 years (since 1937), and were originally made of latex [12]. The current pessaries are made of silicone with non-allergenic material.

Treatment using silicone pessaries is a therapeutic measure with few contraindications, low complication rates, and good levels of continued use. Pessary use has a positive impact on quality of life, sexual function, and body image, and promotes a significant reduction in POP symptoms [13].

Pessary fitting is individual and can be indicated for all symptomatic stages of POP [14]. Vaginal pessaries are also associated with increased frequency and satisfaction of sexual intercourse [15]. The ring device without a membrane is the most frequently used type, allowing sexual activity and retaining a lower amount of vaginal secretion than occlusive (Gellhorn) types or those with a membrane [16, 17].

Although the condition does not increase mortality, the symptoms secondary to the dysfunction can have a major effect on the quality of life of women, with physical, psychosocial, and economic impacts [18].

\section{Objectives}

The primary objectives of the present study were to assess the impact and effectiveness of vaginal pessary use on the quality of life of women with advanced POP and to determine the level of satisfaction with using the pessary and with the care provided by the multidisciplinary team.

The secondary objective was to identify the main reasons for discontinuing pessary use.

\section{Materials and methods}

A multicenter, longitudinal prospective observational study was conducted at the Urogynecology Sector of the Department of Gynecology of the Hospital Ipiranga (November 2017 to May 2019), and the Sector for Urogynecology and Vaginal Surgery of the Hospital Central da Irmandade da Santa Casa de Misericórdia de São Paulo, during the period spanning July 2019 to January 2021. There was a minimum of 6 months follow-up.

This study was carried out before and during the COVID19 pandemic. It did not change the method of recruiting the patients. Despite this, we offered another form of treatment for those who could not benefit from elective surgery.

During the period when there was the greatest number of cases of COVID-19 infections, elective surgeries were suspended in Brazil. However, medical consultations were maintained, observing care protocols, which included individual patient care, mandatory use of masks, cleaning of the stretcher with $70 \%$ alcohol, hand hygiene through washing with soap and water, and the use of gloves. Thus, patients with POP were selected for the use of the pessary and attended to in return appointments.

Given that the device is for permanent individual use with different sizes, we recommend that the patient purchase the ring model without a membrane from a vendor that is most affordable for them, involving no conflicts of interest. Pessary treatment would be prescribed for these women without a desire for surgery or with clinical risks, regardless of participation in the study.

The POP was categorized into stages using the POP-Q method according to Bump's 1996 classification (Fig. 1) [19]. Stage III is considered to be when the distal-most portion of the prolapse protrudes more than $1 \mathrm{~cm}$ below the hymen but protrudes no farther than $2 \mathrm{~cm}$ less than the total

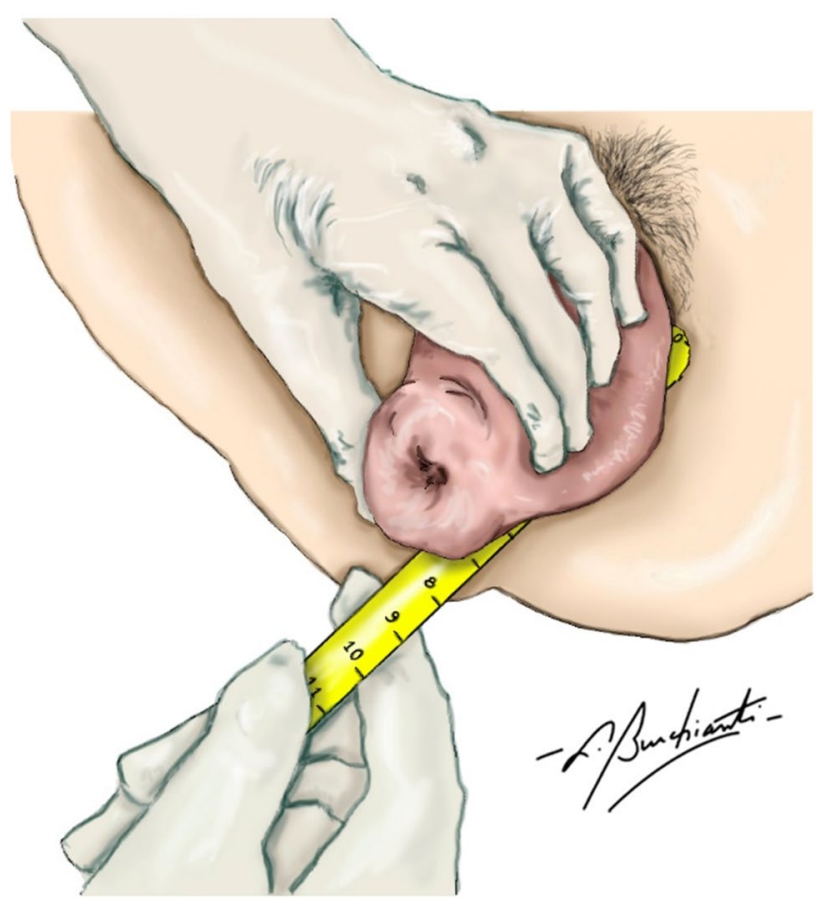

Fig. 1 Measurement representation of the pelvic organ prolapse stage IV according to the POP-Q method (Art by L.C. Burchianti and production by B.B. Zeiger) 
vaginal length. Stage IV is when vaginal eversion is essentially complete.

The doctor performed the clinical examination using vaginal touch with two fingers, with the index finger positioned posteriorly to the midline of the pubic symphysis and the middle finger positioned on the posterior vaginal wall. The practitioner measured the approximate distance between the two fingers in centimeters and indicated the size of pessary to be used. The patient returned on a second visit with the purchased silicone pessary. The Brazilian Public Health System (SUS) provides the POP treatment for free, such as all visits and surgery, but does not provide the pessary for free; therefore, the patients needed to buy the pessary for conservative management.

After agreeing to take part in the study and signing the free and informed consent form, the questionnaires, previously translated into and validated in Portuguese; the ICIQVS [20] for functioning of vaginal, sexual symptoms, and quality of life; and the SF-12 v2 [21] measuring quality of life, were then applied individually both at the first consultation and again after 6 months.

In addition to the quality of life and subjective assessment questionnaires, a sociodemographic questionnaire was applied at the Ipiranga Hospital and Irmandade da Santa Casa de Misericórdia de São Paulo, collecting data on age, marital status, comorbidities, delivery type, and parity.

After conducting the interview with the questionnaires, a subjective assessment comprising four questions were performed: were you satisfied with the treatment? Would you approve and recommend this to other patients with the same condition? Did you feel well cared for by the medical and nursing teams? Did your urinary symptoms improve or worsen after using the pessary?

Local estrogen use was prescribed for all patients who used the pessary, except for one patient with breast cancer.

Initially, there was 97 women attempting the pessary use. After initial pessary fitting, patients were asked to return after 30 days. The medical doctors and residents taught the patients self-management, to be self-limited, and their family in case of difficulties managing it alone. Patients with no handling difficulties were asked to return every 60 days for follow-up. The cleaning protocol was established every 15 days to the women with no handling difficulties and sexual activity or every 30 days with the hospital team to the patients with no family help or no self-management.

A total of 88 participants completed the two stages of the study, comprising 40 women at the Hospital Ipiranga and 48 women at the Irmandade Santa Casa de Misericórdia de São Paulo. Of the total of 97 women, 9 patients (9.3\%) discontinued or were excluded for not completing the minimum required period for adaptation of the device at the first return medical visit (after 30 days) and after two pessary refitting attempts in cases of retention failure. The pessary was indicated for 97 women, and the success rate was defined by the 88 woman who felt satisfied with the device and remained under treatment for at least 6 months.

\section{Inclusion criteria}

The inclusion criteria were: agreeing to take part in the study and answering the questionnaire; the presence of POP stages III and IV; patients who not had previously used a pessary prior to the start of the present analysis.

\section{Exclusion criteria}

The exclusion criteria were: patients allergic to silicone (inert pessary material), patients with cognitive disorders that prevented understanding of treatment or the qualityof-life questionnaire; individuals with cervical or ovarian cancer; patients who refused to purchase the pessary.

\section{Discontinuation criteria}

The criteria for discontinuation were: loss of outpatient follow-up for over 6 months after two attempts at contacting by telephone; pessary retention failure after two refitting attempts or the impossibility of buying another size; not having adapted to the pessary after at least 30 days.

\section{Sample size and participants}

Every patient of the Urogynecology Sector of the Department of Gynecology of the Hospital Ipiranga, and the Sector for Urogynecology and Vaginal Surgery of the Hospital Central da Irmandade da Santa Casa de Misericórdia de São Paulo, from November 2017 to May 2019 and July 2019 to January 2021 respectively, who met the inclusion criteria, were invited to participate in the study. Therefore, the included participants were chosen from a convenience sample.

\section{Statistical analysis}

The characteristics of the study participants were expressed as mean and standard deviation for quantitative variables, with a tendency for normal distribution, and as median with interquartile range for nonparametric variables. Qualitative variables were expressed as absolute and relative frequency. Student's $t$ test, the Mann-Whitney test and Fisher's exact test were applied respectively, according to the variables of interest and study site.

A significance level of $p<0.05$ was adopted and all statistical analyses were carried out using the statistical software Stata, version 15.1. 


\section{Ethical aspects}

The project was approved by the Research Ethics Committee of the Hospital Ipiranga under permit CAAE 77,037,317.4.0000.5488 (versions 1 and 2) and the Irmandade da Santa Casa de Misericórdia de São Paulo, as the co-participating hospital on the Brazil platform under permit CAAE 77,037,317.4.2001.5479.

\section{Results}

The pessary was indicated for 97 women, and the success rate $90.72 \%$ (88-97) with complete adherence and a high level of satisfaction with treatment among study participants (75.3\%) with the device for at least 6 months of use (Fig. 2).

All women invited to participate in the study who met the inclusion criteria accepted. In the present study, 97 women were included. The sociodemographic data are shown in Table 1, including number of pregnancies, type of delivery, marital status, sexually active, and comorbidities. The median age of participants was 71.5 (65-76) years and the median number of pregnancies was 4 (3-5), deliveries were predominantly vaginal $(82.5 \%)$.

Only 16 women $(16.5 \%)$ reported being sexually active. The other women have not become sexually active after pessary use owing to problems with their partner or widowhood. The group of 16 was sexually active before and after pessary use and they reported an improvement in sexual symptoms after using the pessary (78.6\%) and also improved their relationship with the partner.

In the study 17 (17.5\%) experienced pessary expulsion (completely expelled) within the first 4 weeks of treatment and 10 women had a second pessary fitted and became adapted. Nine women were entered into the study and discontinued the treatment $(9.3 \%)$ by not completing the
6 months, comprising 7 because of pessary expulsion, 1 because they desired surgery, and 1 because of a worsening of urinary conditions (Table 2).

At both centers involved, patients felt well cared for by the medical teams. Satisfaction with the pessary based on subjective rating was $83.3 \%$ at the Hospital Ipiranga and 69.1\% at the Irmandade da Santa Casa de Misericórdia de São Paulo $(p=0.107)$, whereas ratings for quality of care provided were $90.4 \%$ and $86.8 \%$ at the respective study venues ( $p=0.606$; Fig. 3$)$.

As measured by the ICIQ-VS and the SF-12 V2, an improvement in quality of life was evident for the different domains after commencing pessary treatment across all components assessed for the samples from both hospitals (Table 3). There was a higher percentage improvement for aspects related to vaginal functioning (91.8\%) and quality of life $(92.8 \%)$; (as measured by the ICIQ-VS), mental health $(80 \%)$, and role of emotions $(77 \%)$; (as measured by SF-12).

\section{Discussion}

In the present study, vaginal pessary use proved to be 90.7\% effective, corroborating the results of Clemons et al. [22], in which $92 \%$ of women were satisfied with pessary use after a 2-month follow-up.

Vaginal devices should not be prescribed only as an alternative, but should be offered as a first option, for the first line of treatment for symptomatic POP patients before indicating surgical procedures, given that the rates of satisfaction and acceptance are 70-92\%, according to Lamers et al. [11]. In the present multicenter study, participants reported a high level of satisfaction $(75.3 \%)$, with rates in line with the author Lamers et al. [11].

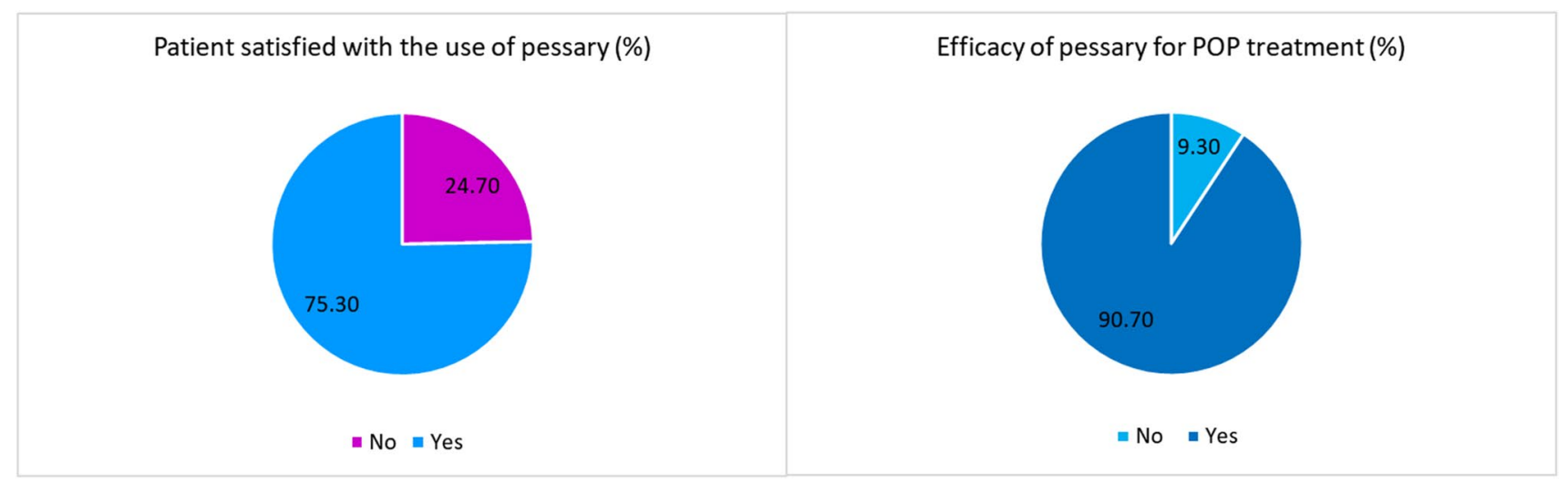

Fig. 2 Satisfaction index and efficacy with the use of the pessary for the treatment of pelvic organ prolapse (POP) among 97 women participating in the study. São Paulo, 2021 
Table 1 Characteristics of women treated at the urogynecology clinic in the use of pessary and users of the Hospital Ipiranga or Hospital Santa Casa. São Paulo, 2021

\begin{tabular}{|c|c|c|}
\hline & $\mathrm{N}$ & $\%$ \\
\hline Total & 97 & 100 \\
\hline \multicolumn{3}{|l|}{ Demographic and parity characteristics } \\
\hline Age (median, IQR) & 71.5 & $(65-76)$ \\
\hline \multicolumn{3}{|l|}{ Marital status } \\
\hline Married & 38 & 39.2 \\
\hline Divorced & 11 & 11.3 \\
\hline Widow & 28 & 28.9 \\
\hline Single & 5 & 5.2 \\
\hline Not stated & 8 & 8.2 \\
\hline Number of pregnancies (median, IQR) & 4 & $(3-5)$ \\
\hline Women with twin pregnancies & 10 & 10.3 \\
\hline \multicolumn{3}{|l|}{ Delivery type $\mathrm{e}^{\mathrm{a}}$} \\
\hline Vaginal & 80 & 82.5 \\
\hline Cesarean & 26 & 26.8 \\
\hline Forceps & 14 & 14.4 \\
\hline Miscarriage & 26 & 26.8 \\
\hline \multicolumn{3}{|l|}{ Women sexually active } \\
\hline No & 81 & 83.50 \\
\hline Yes & 16 & 16.49 \\
\hline \multicolumn{3}{|c|}{ Comorbidities and distribution of most common diseases } \\
\hline \multicolumn{3}{|l|}{ Comorbidities reported $^{\mathrm{c}}$} \\
\hline No & 41 & 42.3 \\
\hline Yes & 56 & 57.7 \\
\hline \multicolumn{3}{|l|}{ Arterial hypertension } \\
\hline No & 52 & 53.6 \\
\hline Yes & 45 & 46.4 \\
\hline \multicolumn{3}{|l|}{ Diabetes mellitus } \\
\hline No & 75 & 77.3 \\
\hline Yes & 22 & 22.7 \\
\hline
\end{tabular}

$I Q R$ interquartile range

${ }^{a}$ Women with at least one delivery matching the reported characteristics

${ }^{\mathrm{b}}$ Comorbidity was defined as having two or more diseases from among hypertension, diabetes, or dyslipidemia

Deliveries were predominantly vaginal $(82.5 \%)$, followed by cesarean and miscarriage $(26.8 \%)$, and forceps (14.4\%). Patients were multiparous and had mixed delivery types. In the study by DeLancey [4], vaginal delivery was the main risk factor for prolapse, but this factor alone fails to explain the occurrence of the disorder, because it is also present in nulliparous women.

The vaginal pessary is indicated for patients who do not wish to undergo surgery or who have surgical contraindications, such as older age and clinically uncontrolled comorbidities. The results showed that in the two hospitals combined, $57.7 \%$ of patients reported comorbidities, with hypertension (46.4\%) and diabetes $(22.7 \%)$ being the most prevalent. Indications for the conservative approach can promote immediate relief of symptoms and reduce the risk of surgical morbidity. The presence of clinically uncompensated conditions justifies the use of a pessary in view of surgical contraindication.

If surgical intervention is required, the pessary can provide symptom relief while awaiting the procedure. Furthermore, during the period of the pandemic the pessary represents an alternative for women who cannot benefit from surgical treatment.

The ring model was chosen for this study because it is the most frequently used and it has better acceptance, in addition to enabling sexual activity without the need to remove the device [17]. The POP has a negative impact on sexual function. Only $16(16.5 \%)$ women reported being sexually active, the low number being explained by widowhood, age, problems with their partner, or advanced prolapse. This group reported an improvement in sexual symptoms after using the pessary $(78.6 \%)$ that may result from the use of the pessary together with the use of estriol vaginal cream, providing an improvement in lubrication.

The main reasons for discontinuing treatment were pessary expulsion $(7.2 \%)$, desire for surgery (1\%), and worsening stress urinary incontinence (1\%). Retention failure was the main factor in discontinuation, corroborating the study by Fernando et al. [23]. In the literature, pessary retention failure rates vary widely, ranging from 25 to 59\% [22-24].

The study drop-out rate was low $(9.3 \%)$ compared with the $49.1 \%$ in the review by Coelho et al [16]. The main causes of discontinuation in the cited review were failure to retain the pessary, discomfort, desire for surgery, and difficulties handing the device.

These complaints may be remedied by further adaptation of the method. According to Barros et al. [25], the longer the follow-up, the greater the chances of clearing up doubts and identifying complications, such as dropping, discomfort, and increased vaginal secretion. Expulsion of the pessary can be resolved by switching to a larger device and if the patient failed to adapt, other models can be tried. The author observed that one of the most common issues ( $12 \%$ of cases) involved problems fitting the device (owing to poor anatomical knowledge or lack of family support).

The women who recommended the pessary to others with the same disorder were those who were satisfied with the treatment and care provided by the team. Applying the skill of active listening and employing the tools needed to provide the best possible care are strategies that ensured the success of the study.

According to some evidence that estrogen protects against complications in pessary users, no cases of ulceration or serious complications, such as fistulas or incarceration, were found in the present study. 
Table 2 Characteristics of treatment with vaginal pessary at Hospital Ipiranga and Hospital Santa Casa. São Paulo, 2021

Fig. 3 Comparison between percentage of satisfaction with the use of the pessary and perception of reception by the multidisciplinary team of patients participating in the study, according to the research center. São Paulo, 2021

\begin{tabular}{|c|c|c|c|c|c|c|}
\hline & \multicolumn{2}{|c|}{ Total $(n=97)$} & \multicolumn{2}{|c|}{ Hospital Ipiranga $(n=42)$} & \multicolumn{2}{|c|}{$\begin{array}{l}\text { Hospital Santa } \\
\text { Casa }(n=55)\end{array}$} \\
\hline & $N$ & $\%$ & $n$ & $\%$ & $n$ & $\%$ \\
\hline \multicolumn{7}{|c|}{ Pessary expulsion reported ${ }^{a}$} \\
\hline No & 80 & 82.5 & 39 & 92.9 & 41 & 74.6 \\
\hline Yes & 17 & 17.5 & 3 & 7.1 & 14 & 25.4 \\
\hline \multicolumn{7}{|l|}{ Second pessary fitted ${ }^{\mathrm{b}}$} \\
\hline No & 7 & 7.2 & 1 & 2.4 & 6 & 10.9 \\
\hline Yes & 10 & 10.3 & 2 & 4.8 & 8 & 14.5 \\
\hline \multicolumn{7}{|c|}{ Pessary treatment discontinued } \\
\hline No & 88 & 90.7 & 40 & 95.2 & 48 & 87.3 \\
\hline Yes & 9 & 9.3 & 2 & 4.8 & 7 & 12.7 \\
\hline \multicolumn{7}{|c|}{ Reasons for discontinuing treatment } \\
\hline Pessary expulsion & 7 & 7.2 & 1 & 2.4 & 6 & 10.9 \\
\hline Surgical desire & 1 & 1.0 & 1 & 2.4 & 0 & - \\
\hline Worsening SUI & 1 & 1.0 & 0 & - & 1 & 1.8 \\
\hline
\end{tabular}

SUI stress urinary incontinence

${ }^{a}$ Expulsion was defined as pessary retention failure within the first 4 weeks of treatment, after two refitting attempts

${ }^{\mathrm{b}}$ Second pessary fitted after pessary expulsion

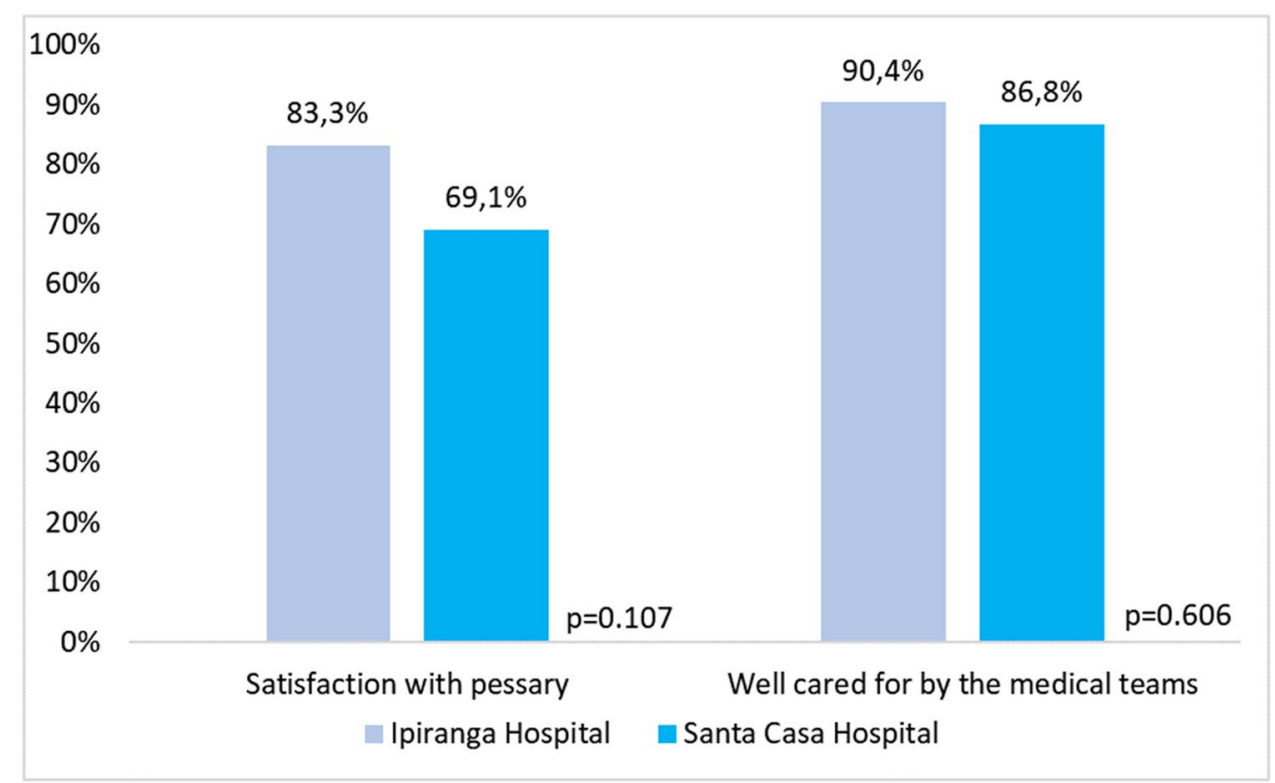

Vaginal pessary treatment was shown to have good continuity rates, with a positive impact on improving sexual function, mental health, and quality of life.

The study had some strengths and limitations. Limitations include the fact that the pessary is not provided for free. This study was carried out in women who were financially able to buy the pessary and thus enable this treatment option.

Strengths include the fact that there is a large number of patients with POP with disorders related to quality of life and sexual disorders. Pessary use has shown high success and satisfaction rates for women who undergo this conservative treatment and the patients can benefit from good results related to improvement of quality of life, without running the risk of a surgical procedure.

Use of vaginal pessaries is an effective treatment strategy for women who do not want a surgical procedure or who cannot undergo a surgical procedure owing to contraindications. The Brazilian Public Health System provides the surgical treatment for free, but there is a waiting time of approximately 2 years. Also, during the period of the 
Table 3 Distribution and comparison of mean and median scores for sexual and vaginal functioning components related to prolapse and quality of life pre- and post-pessary use and percentage of women showing improvement of indicators. São Paulo, 2021

\begin{tabular}{|c|c|c|c|c|c|c|}
\hline \multirow{2}{*}{$\begin{array}{l}\text { Treatment duration } \\
\text { Components }\end{array}$} & \multicolumn{2}{|c|}{ Pre-pessary } & \multicolumn{2}{|c|}{ After 6 months } & \multirow{2}{*}{$\begin{array}{l}\% \text { Women with } \\
\text { improvement }\end{array}$} & \multirow[b]{2}{*}{$p$ value } \\
\hline & Median & $\begin{array}{l}\text { Interquartile range/ } \\
\text { standard deviation }\end{array}$ & Median & Interquartile range & & \\
\hline \multicolumn{7}{|l|}{ ICIQ-VS Questionnaire } \\
\hline Vaginal symptoms $^{\text {a }}$ & 15 & $(12-18)$ & 0 & $(0-3)$ & 91.8 & $<0.001$ \\
\hline Sexual symptoms ${ }^{\mathrm{a}}$ & 11 & $(7.5-15.5)$ & 0.5 & $(0-6.5)$ & 78.6 & 0.002 \\
\hline Quality of life ${ }^{b}$ & 9.2 & \pm 1.7 & 1.4 & \pm 2.9 & 92.8 & $<0.001$ \\
\hline \multicolumn{7}{|l|}{ SF-12 Questionnaire } \\
\hline Physical functioning ${ }^{\mathrm{a}}$ & 0 & $(0-50)$ & 100 & $(100-100)$ & 70.9 & $<0.001$ \\
\hline Physical role ${ }^{\mathrm{a}}$ & 25 & $(25-75)$ & 100 & $(93.7-100)$ & 74.4 & $<0.001$ \\
\hline Body pain ${ }^{\mathrm{b}}$ & 62.1 & \pm 34.8 & 92.5 & \pm 20.9 & 53.0 & $<0.001$ \\
\hline General health $^{\mathrm{a}}$ & 25 & $(0-25)$ & 84 & $(61-100)$ & 74.1 & $<0.001$ \\
\hline Vitality $^{\mathrm{a}}$ & 25 & $(25-50)$ & 75 & $(37.5-100)$ & 54.7 & 0.001 \\
\hline Social functioning ${ }^{\mathrm{a}}$ & 50 & $(25-100)$ & 100 & $(100-100)$ & 63.0 & $<0.001$ \\
\hline Emotional role $^{\mathrm{a}}$ & 25 & $(25-75)$ & 100 & $(93.7-100)$ & 77.0 & $<0.001$ \\
\hline Mental health ${ }^{\mathrm{b}}$ & 35.9 & \pm 25.4 & 78.0 & \pm 25.6 & 80.0 & $<0.001$ \\
\hline
\end{tabular}

${ }^{a}$ Median, interquartile range and Mann-Whitney test performed

${ }^{\mathrm{b}}$ Mean, \pm standard deviation and Student's $t$ test performed

greatest number of COVID-19 infections, elective surgeries were suspended. The patients were able to relieve their symptoms and improve their quality of life while waiting for a surgical procedure.

\section{Conclusions}

Vaginal pessary use had $90.7 \%$ efficacy, a high level of treatment satisfaction $(75.3 \%)$, and a consequent impact on improvement of vaginal and sexual symptoms, quality of life and mental health.

Significant improvement was seen across all domains assessed by the ICIQ-VS and SF12 questionnaires.

The main reasons for discontinuing treatment were pessary expulsion, desire for surgery, and worsening stress urinary incontinence.

The low drop-out rates in the present study (9.3\%) might be attributed to the quality of care provided. At both of the hospital sites assessed, the patients reported being well cared for by the multidisciplinary teams.

Authors' contribution BB Zeiger: Project Development, Data Collection, Manuscript Writing, and Editing.

SS Carramão: Project Development.

CA Del Roy: Project Development.

TT Silva: Patient Selection.

S Hwang: Data Collection.

APF Auge: Project Development.

\section{Declarations}

Conflicts of interest None.

\section{References}

1. Jelovsek JE, Barber MD. Women seeking treatment for advanced pelvic organ prolapse have decreased body image and quality of life. Am J Obstet Gynecol. 2006;194(5):1455-61. https://doi.org/ 10.1016/j.ajog.2006.01.060.

2. Subak LL, Waetjen LE, van den Eeden S, Thom DH, Vittinghoff E, Brown JS. Cost of pelvic organ prolapse surgery in the United States. Obstet Gynecol. 2001;98(4):646-51. https://doi.org/10. 1016/s0029-7844(01)01472-7.

3. Boyles SH, Weber AM, Meyn L. Procedures for pelvic organ prolapse in the United States, 1979-1997. Am J Obstet Gynecol. 2003;188(1):108-15. https://doi.org/10.1067/mob.2003.101.

4. DeLancey JOL. The hidden epidemic of pelvic floor dysfunction: achievable goals for improved prevention and treatment. Am J Obstet Gynecol. 2005;192(5):1488-95. https://doi.org/10.1016/j. ajog.2005.02.028.

5. DATASUS. Demográficas e socioeconômicas. http://datasus. saude.gov.br/informacoes-de-saude/tabnet/demograficas-e-socio economicas. 2000.

6. Silva Filho AL, Fonseca AMRM, Camilatto ES, Cangussu RO. Análise dos recursos para reabilitação da musculatura do assoalho pélvico em mulheres com prolapso e incontinência urinária. Fisioter Pes. 2013;20(1):90-6. https://doi.org/10.1590/S1809-29502 013000100015.

7. Instituto Brasileiro de Geografia e Estatística (IBGE), Fundo de População das Nações Unidas (UNFPA). Indicadores sociodemográficos prospectivos para o Brasil 1991-2030. 2006. http:// www.unfpa.org.br/Arquivos/PDS_Sociodemographic_indicators. pdfgov.br/home/estatistica/populacao/projecao_da_populacao/ publicacao_UNFPA.pdf. Acessed 5 Feb 2008. 
8. Petros P. The integral system. Cent European J Urol. 2011;64(3):110-9.

9. Haylen BT, Maher CF, Barber MD, Camargo S, Dandolu V, Digesu A, et al. An International Urogynecological Association (IUGA)/International Continence Society (ICS) joint report on the terminology for female pelvic organ prolapse (POP). Int Urogynecol J. 2016;27(2):165-94.

10. Büyükbayrak EE, Yilmazer G, Özyapi AG, Kars B, Karsidag AYK, Turan C. Successful management of uterine prolapse during pregnancy with vaginal pessary: a case report. J Turk Ger Gynecol Assoc. 2010;11(2):105-6.

11. Lamers BHC, Broekman BMW, Milani AL. Pessary treatment for pelvic organ prolapse and health-related quality of life: a review. Int Urogynecol J. 2011;22(6):637-44. https://doi.org/10.1007/ s00192-011-1390-7.

12. Teixeira AS. Faculdade de educação e meio ambiente, pp 1-45. 2011.

13. Coelho SCA, Giraldo PC, Florentino JO, de Castro ED, Brito LGO, Juliato CRT. O uso de pessário vaginal pode alterar a flora microbiológica? Um estudo transversal. Rev Bras Ginecol Obstet. 2017;39(4):169-74.

14. McIntosh L. The role of the nurse in the use of vaginal pessaries to treat pelvic organ prolapse and/or urinary incontinence: a literature review. Urol Nurs. 2005;25(1):41-8.

15. Patel M, Mellen C, O'Sullivan DM, LaSala CA. Impact of pessary use on prolapse symptoms, quality of life, and body image. Am J Obstet Gynecol. 2010;202(5):499.e1-.e4. https://doi.org/10. 1016/j.ajog.2010.01.019

16. Coelho SCA, de Castro EB, Juliato CRT. Female pelvic organ prolapse using pessaries: systematic review. Int Urogynecol J. 2016;27(2):1797-803. https://doi.org/10.1007/ s00192-016-2991-y.

17. Mao M, Ai F, Kang J, Zhang Y, Liang S, Zhou Y, Zhu L. Successful long-term use of Gellhorn pessary and the effect on symptoms and quality of life in women with symptomatic pelvic organ prolapse. Menopause. 2009;26(2):145-51. https://doi.org/10.1097/ GME.0000000000001197.
18. Silva CHM. Manual SOGIMIG de Uroginecologia. 1st ed. Rio de Janeiro: Med Book; 2019. p. 145-55.

19. Bump RC, Mattiasson A, B $\varnothing \mathrm{K}$, et al. The standardization of terminology of female pelvic organ prolapse and pelvic organ dysfunction. Am J Obstet Gynecol. 1996;175(1):10-7.

20. Tamanini JTN, Almeida FG, Girotti ME, Riccetto CLZ, Palma PCR, Rios LAS, et al. The Portuguese validation of the International Consultation on Incontinence Questionnaire-Vaginal Symptoms (ICIQ-VS) for Brazilian women with pelvic organ prolapse. Int Urogynecol J. 2008;19(10):1385-91. https://doi.org/10.1007/ s00192-008-0641-8.

21. Silveira MF, Almeida JC, Freire RS, Haikal DS, Martins AEBL. Psychometric properties of the quality of life assessment instrument: 12-item health survey (SF-12). Ciên Saúde Colet. 2013;18(7):1923-31. https://doi.org/10.1590/s1413-8123201300 0700007.

22. Clemons JL, Aguilar VC, Tillinghast TA, Jackson ND, Myers DL. Patient satisfaction and changes in prolapse and urinary symptoms in women who were fitted successfully with a pessary for pelvic organ prolapse. Am J Obstet Gynecol. 2004;190(4):1025-9. https://doi.org/10.1016/j.ajog.2003.10.711.

23. Fernando RJ, Thakar R, Sultan AH, Shah SM, Jones PW. Effect of vaginal pessaries on symptoms associated with pelvic organ prolapse. Obstet Gynecol. 2006;108(1):93-9. https://doi.org/10. 1097/01.AOG.0000222903.38684.cc.

24. Maito JM, Quam ZA, Craig E, Danner KA, Rogers RG. Predictors of successful pessary fitting and continued use in a nurse-midwifery pessary clinic. J Midwifery Womens Health. 2006;51(2):78-84. https://doi.org/10.1016/j.jmwh.2005.09.003.

25 Barros CR, Machado RBB, Camargo ACM, Gollop TR. Tratamento conservador de prolapso de órgão pélvico com pessário: revisão de literatura. Rev Med. 2018;97(2):154-9. https://doi.org/ 10.11606/issn.1679-9836.v97i2p154-159.

Publisher's note Springer Nature remains neutral with regard to jurisdictional claims in published maps and institutional affiliations. 